\title{
Relying on serendipity is not enough
}

\section{Building a resilient health sector in India}

\author{
Indrani Gupta ${ }^{1}$
}

Published online: 19 August 2020

(c) Editorial Office, Indian Economic Review 2020

\begin{abstract}
The novel coronavirus has caused a global public health crisis, and impacted countries irrespective of their development status. The health system preparedness has varied across countries, necessitating a hard look at how resilient health systems can be built to withstand the onslaught of sudden pandemics and epidemics. India has been grappling with the onslaught of COVID-19 since the last 6 months of the current year, bringing into focus the ability of its health system to withstand the pressures of dealing with such a pandemic. In this context, the paper analyses India's health sector by focusing on infrastructure, personnel, financing and governance, to enable a better understanding of the extent of resilience in India's health system. Using data from the latest household survey on health, the paper also looks at the disease profile of care seekers to illustrate why COVID transmission is likely to be rapid in the country, the potential impact of COVID care on non-COVID care, the groups that are most likely to forego care due to the lockdown and the diversion of resources to COVID care, choice of providers and out-of-pocket expenditure evidenced from such choice. The paper concludes that a country cannot effectively deal with a pandemic and reduce its socioeconomic impact by trying to fix its health system in real time. The lesson from the COVID era would be for India to immediately start with the much delayed health sector reforms, beginning with a substantial jump in public health financing, if impact of future epidemics and pandemics are to be minimised.
\end{abstract}

Keywords India $\cdot$ Demand for care $\cdot$ Pandemic preparedness $\cdot$ Health sector reforms $\cdot$ Health financing

JEL Classification $\mathrm{I} 12 \cdot \mathrm{I} 18 \cdot \mathrm{H} 12 \cdot \mathrm{H} 51$

Indrani Gupta

indrani@iegindia.org

1 Institute of Economic Growth, Delhi University Enclave, Delhi 110007, India 


\section{Introduction}

The COVID-19 pandemic has generated a renewed interest in the health sector globally. In developed countries that are most affected, the health sector has been relatively better prepared due to decades of high investment and strong health systems. Despite this, death rates have been high in Europe, attributed to timing of the lockdown, infections invading nursing homes and care homes, and also health systems caught off-guard by the onslaught of cases (Burn-Murdoch and Giles 2020). The death rates have been highest among the elderly population in many of these countries, including the USA, where $80 \%$ of total deaths are among those 65 and older (Centers for Disease Control and Prevention 2020).

The ability of health systems to cope with the onslaught of high volume of COVID-19 cases has varied across countries, and the response of countries has also been disparate, with varying degrees of success. Many of these countries have also worried about non-COVID care during the pandemic. A study documented how routine care for chronic diseases has been adversely impacted due to the pandemic; diabetes, chronic obstructive pulmonary disease, hypertension and mental health were some of the most impacted areas of concern during the COVID crisis (Chudasama et al. 2020). Others have documented the negative impact on cancer care, dental care and also routine care (Harky et al. 2020; Devi and Milevska-Kostova 2020). The squeezing out of health care for non-COVID patients has important implications about the overall morbidity and mortality, health care costs and socioeconomic impact on households. This is, of course, in addition to the COVID-related impact on all these parameters. The actual impact of the pandemic on overall health indicators and treatment-seeking behaviour may spread over a substantial time period, but can only be assessed once the crisis is over.

The extent to which health services will be stretched for the population will depend to a large extent on the health systems preparedness of a country. In this paper, we look at available evidence on (a) India's current situation with COVID and factors that indicate the possibility of a quicker spread of COVID, (b) health sector preparedness to tackle high volume of cases including levels of health financing, (c) the possible impact on non-COVID health care and (d) health financing situation in the country.

In the absence of databases on treatment-seeking behaviour during COVID, we use secondary data to analyse these three issues. For global comparisons on COVID testing and other parameters, the database Our World in Data is used. The latest round of the National Sample Survey data on health-the 75th roundis used to assess the disease profile as well as individual treatment-seeking behaviour. The data on availability of health facilities and health personnel is obtained from the latest National Health Profile (NHP) 2019, published by the Central Bureau of Health Intelligence under the Directorate General of Health Services of the Ministry of Health and Family Welfare (MOHFW). We also look at data put out by the Reserve Bank of India (RBI) and the latest National Health Accounts for 2016-2017 published by the MOHFW for health financing indicators. There 
are numerous articles, commentaries, blogs and other materials on COVID available online-published and unpublished, and these are valuable sources of information on the pandemic. We use those that seem the most reliable wherever information is not available from the sources mentioned above.

\section{The pandemic in India}

COVID cases in India have been increasing rapidly, especially after the partial removal of lockdown and massive movement of migrant populations. On July 30, total cases in India were 15,77,271 with total deaths of 34,951. Tests have been ramped up and daily tests have also increased significantly over the last several weeks. With the lockdown being gradually removed, cases have seen a surge, with Maharashtra, Tamil Nadu, Delhi, Karnataka, Andhra Pradesh being some of the most affected states in terms of total confirmed cases.

Low testing was initially mainly out of compulsion because of shortages of testing kits and low capacities of government laboratories-both in numbers and ability to analyse the samples. However, domestic capacity has been vastly increased over the past few months and India can now test more than 3,00,000 samples a day and plans to increase testing further. The government has also enlisted private laboratories for testing. Currently, 907 government and 414 (ICMR 2020) private laboratories have been enlisted for COVID-19 testing, resulting in a very rapid improvement in the testing situation.

To compare India's test figures with other countries with high burden, we use information on tests per 1000 from Our World in Data, one of the few sources of global data on COVID parameters.

The test units are somewhat disparate, making comparisons a bit problematic. For Chile, Brazil, Russia, Italy, Spain, Germany, Switzerland and Iran, the numbers pertain to total tests performed. For Peru, South Korea and UK, the numbers pertain to people tested. For India, the information is on samples tested. For USA the units are unclear, according to the source. Nevertheless, one can get some insights into the scale of testing done in these countries.

India's testing numbers remain very low despite significant increases in daily tests (Fig. 1). The actual number of people tested per 1000_instead of sampleswould actually be much lower. India's testing number seems closer to Brazil's and Peru's, but it must be recalled that India had its first corona case in January, whereas Brazil and Peru had it about 2 months later. Also for Peru the number pertains to people tested.

The correlation between total cases and total tests performed is very high, as can be seen from Fig. 2a, indicating that higher testing is bringing out higher cases. However, in the recent past, the linear relationship is weaker, and there seems to be a faster increase in cases compared to tests, indicating the possibility of community transmission. Plotting new cases against new tests (Fig. 2b), this trend is clearer and seems to have started somewhat earlier, around the beginning of June. 


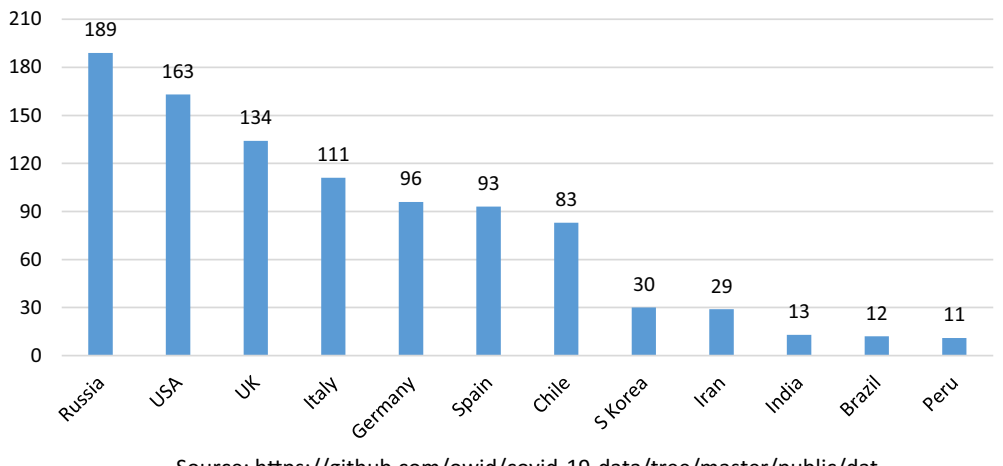

Fig. 1 COVID-19 tests per thousand, 21-29 July, 2020
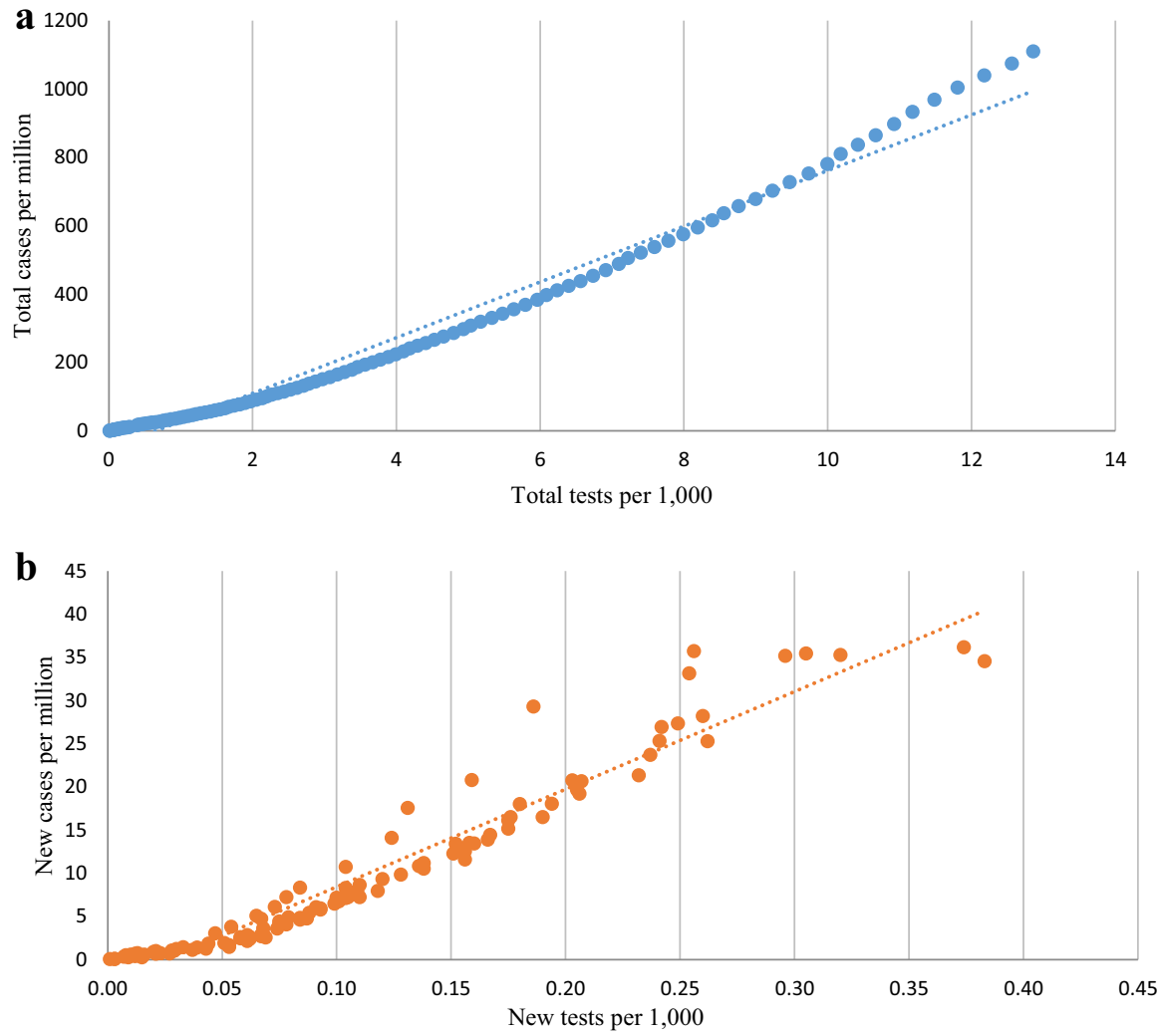

Fig. 2 a New cases per million and new tests per thousand, 29 March-29 July, 2020. b Total cases per million and total tests per thousand, 29 March-29 July, 2020 

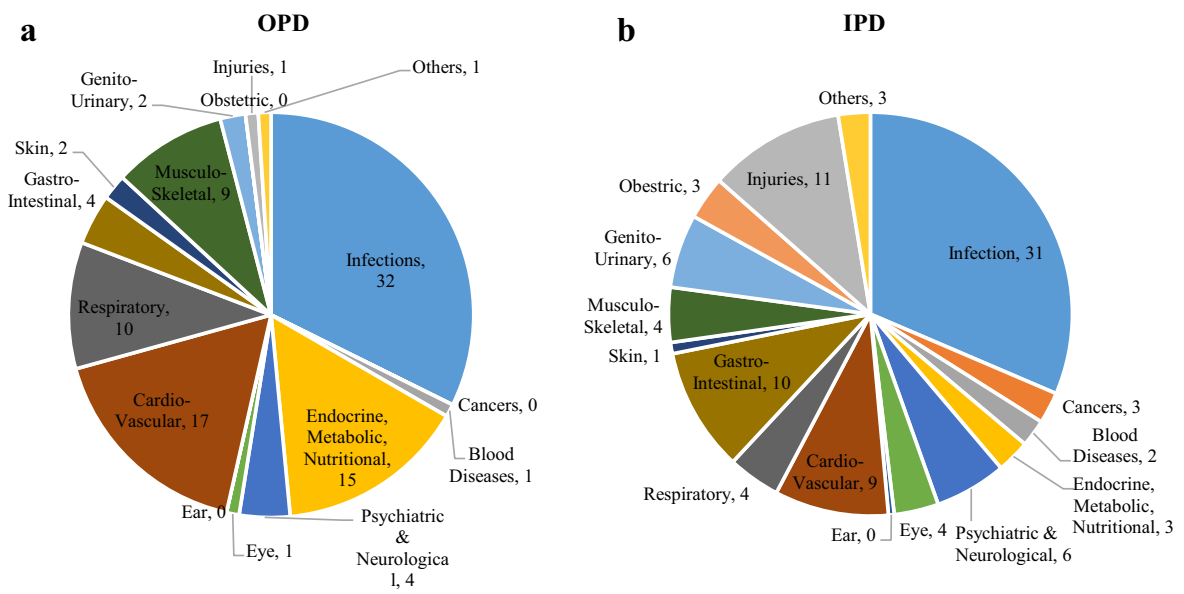

Fig. 3 a and $\mathbf{b}$ Share of disease groups in OPD and IPD care (\%), NSS 75th round

As for doubling time, India's average on June 30 was 19 days, which is an improvement over the May figure of about 15 days. However, the world average on the same day was 56 days, indicating that India is still in the rapid spread phase.

With the lockdown being removed mostly, is it fair to expect that infections will increase rapidly? Even as late as in the second week of June, the government maintained that there was no community transmission in India, and the Home Minister has stated that Delhi-which has seen an explosion of cases-is not in community transmission mode (NDTV 2020). Experts have debated and even outright rejected this position of the government, and pointed out many instances of cases where it was not possible to track down the source of infection (Times of India 2020). If tests are ramped up significantly, as has been suggested by experts repeatedly, one can only hope that the cases do not overwhelm the already stretched health services in the country. That can happen if community transmission, has, in fact, not taken hold in the country, as the government has repeatedly been assuring the country.

\subsection{Community transmission and susceptibility to infection}

While there are debates and discussions around community transmission and what defines it, one important pointer towards the possibility of rapid transmission is the presence of infectious diseases in the communities. While household self-reported data may not be the right source to estimate susceptibility precisely, it is, nevertheless, very helpful for understanding how prone India will be to rapid community transmission.

Figure $3 \mathrm{a}, \mathrm{b}$ give the share of infectious diseases in the population that sought care-with a reference period of preceding 15 days from the day of the interview, which we label as out-patient care (OPD) and hospitalisation or in-patient care (IPD) based in the NSS 75th round, which pertains to 2017-2018. 


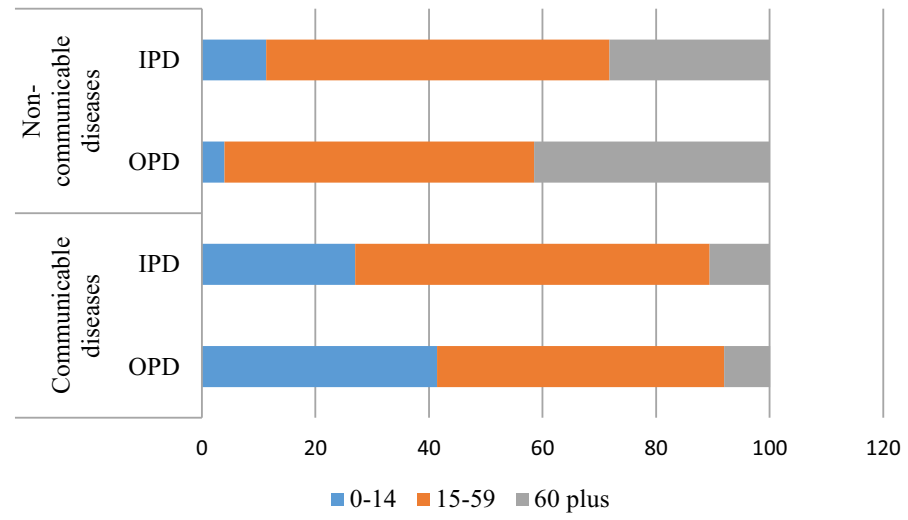

Fig. 4 Share of age categories in communicable and non-communicable diseases, NSS 75th round

For both OPD and IPD, the major share in diseases was that of infections. This is just a confirmation of the fact that India has yet to complete the epidemiological transition and is dealing with the dual burden of communicable and non-communicable diseases. Other studies have confirmed that there is wide variation across Indian states with communicable, maternal, neonatal and nutritional diseases still being a significant presence in many states (Dandona et al. 2017).

It is important to note that for OPD cases, respiratory illnesses is a sizeable share of $10 \%$, separate from infections. These could be asthma, chronic obstructive pulmonary diseases (COPD), emphysema and other such disorders, the presence of which has been seen as aggravating conditions for COVID patients, especially COPD (Zhao et al. 2020). In India, COPD is at the second place in the top 10 causes of deaths in 2017 (IHME 2018).

In the context of COVID, the implication is clear: while the entry of COVID into the country can be traced to international travel, once in, there was always a fairly non-negligible probability that the infection would have spread to others through community transmission. This is because the modes of transmission are going to be fairly similar for COVID and other infectious diseases: lack of social distancing, lack of hygiene and sanitation, congested habitat and lack of awareness. Who are most likely to spread the infection?

Figure 4 gives the shares for the two broad disease categories-communicable and non-communicable diseases - by three age categories (0-14, 15-59 and 60 and above), and shows that in communicable diseases, the share is the highest for the adults between the ages of 15 and 59, closely followed by children.

Given this pattern, it stands to reason that community transmission is going to be happening mostly through the adults. The susceptibility of children to general infections is also high, and while there has not been much evidence of children falling sick due to COVID, it has probably been one of the best aspects of the COVID response in India that schools have been shut down, and children kept relatively safe at home. Some reports of multisystem inflammatory conditions in children have been documented in Europe and North America, and while more data would be 
Table 1 Presence of co-morbidities by age, OPD and IPD, NSS 75th round

\begin{tabular}{lrrrrr}
\hline Conditions & \multicolumn{2}{l}{ OPD } & & \multicolumn{2}{l}{ IPD } \\
\cline { 2 - 3 } \cline { 5 - 6 } \cline { 5 - 6 } & $15-59$ & 60 and above & & $15-59$ & 60 and above \\
\hline Diabetes & 13.0 & 20.8 & & 0.9 & 4.5 \\
Cardiovascular disease & 3.2 & 7.7 & & 4.3 & 19.6 \\
Hypertension & 2.4 & 4.9 & & 1.0 & 5.9 \\
Asthma & 12.1 & 25.7 & & 1.1 & 3.8 \\
Any above 4 conditions & 30.6 & 59.1 & & 7.2 & 33.8 \\
Any NCD & 64.7 & 88.4 & & 31.5 & 77.0 \\
\hline
\end{tabular}

required to link these with COVID (World Health Organization Newsroom 2020), the best approach is to keep them out of harm's way, especially in settings like India, where infections do spread rapidly among children due to a variety of factors.

A quick note about co-morbidities. While adults are supposedly the most robust group in terms of resilience to disease, COVID is also a deadlier infection than many the world has encountered hitherto. Also, there is increasing evidence that comorbidities in adults like hypertension, diabetes, COPD, CVD comprise major risk factors for patients with COVID (Wang et al. 2020; Singh et al. 2020).

The NSS data allows us to understand the occurrence of these diseases in the population. Table 1 presents data on the important co-morbidities in the context of COVID for adults and the elderly.

The data indicates that adults with hypertension, diabetes, heart diseases and asthma seek OPD and IPD care in non-negligible proportions. In fact, a relatively higher proportion of the elderly with any of these conditions seek OPD care compared to the adults. The same is the case for IPD. The data also reveals how prevalent these conditions are: for example, 59\% of the elderly visiting a provider for OPD had at least one of these conditions. The high prevalence of non-communicable diseases are evident from the fact that of all the adults who sought OPD and IPD care, 65\% and $32 \%$ respectively had at least one NCD. Thus, NCDs are well-entrenched in our population, and it is likely that a rapid spread of COVID infection among those with any of these co-morbidities might result in higher number of cases requiring proper and intensive care, especially for the elderly.

While the above table gives the breakup of diseases by age, we turn to look more closely at treatment-seeking behaviour of adults and the elderly in the next section.

\section{Demand for care: who will be impacted the most during the pandemic?}

The demand for care can be looked at across different categories: gender, residence, age categories and consumption quintiles. In Table 2 below, we present treatmentseeking behaviour for OPD and IPD across age categories, for rural and urban India. 
Table 2 Profile of OPD and IPD care-seekers

\begin{tabular}{lrrrrr}
\hline Age category & \multicolumn{2}{l}{ OPD } & & & \multicolumn{2}{l}{ IPD } \\
\cline { 2 - 3 } & Rural & Urban & & Rural & Urban \\
\hline $0-14$ & 5.5 & 6.7 & & 1.6 & 2.3 \\
$15-59$ & 5.6 & 7.1 & & 2.6 & 3.0 \\
$60-69$ & 22.1 & 30.5 & & 6.5 & 8.4 \\
$70-79$ & 27.5 & 38.3 & & 8.9 & 12.0 \\
$80 \&$ above & 31.4 & 42.5 & & 12.4 & 16.9 \\
All & 6.8 & 9.1 & & 2.6 & 3.4 \\
\hline
\end{tabular}

The gender differentials were narrow, so we do not present the results by gender category.

First of all, in rural and urban India, about $6.8 \%$ and $9 \%$ respectively had sought care in the last 15 days previous to the day of the interview, indicating a slightly higher occurrence of ill health and care-seeking in urban India.

However, the most striking result is that the occurrence increases rapidly with increases in age. For example, for rural India, 5.6\% sought OPD care from the age category $15-59$, but this jumped to $22 \%$ for those between 60 and 69 years of age. It increased further to $31 \%$ and $42 \%$ respectively for rural and urban India for the oldest group, 80 and above.

For IPD the occurrence numbers are lower, but the same pattern is observedincrease in demand with age, with the oldest age category showing highest demand. Also, for IPD there is a noticeable difference between male and females, with demand being higher for males.

We also look at the demand for care by quintiles, but due to the potential problem of endogeneity of the wealth variable in treatment seeking behaviour, we do not attempt to interpret this result, which does show a positive income gradient.

The main result in this section is that although infection will spread through mostly the adults, any disruption to the health care system is likely to impact on elderly treatment-seeking behaviour by squeezing out care for this group in the absence of adequate hospital and other services.

We now present some evidence that indicates the reason for the potential squeezing out of health care in the context of COVID.

\section{Assessing pandemic preparedness through the COVID experience ${ }^{1}$}

The WHO defines a pandemic as a "worldwide spread of a new disease" (World Health Organization Diseases 2020), unlike outbreaks and epidemics, which are more community or region-specific spread of an illness or disease, in excess of

\footnotetext{
1 This section is based largely on a recent paper by the author. Relying on serendipity is not enough: fixing the health system in India for future pandemics. IEG Insights Gupta (2020).
} 
"normal expectancy" (WHO Diseases 2020; WHO Humanitarian Health Action 2020). These definitions suggest that in an outbreak or epidemic there may be a reasonable possibility of predicting the occurrence in advance and some preparation can be made to address the situation. Clearly, a pandemic-with a new infection or disease-is difficult to anticipate and, therefore, quicker to spread unless some robust systems are in place to absorb the impact.

Since pandemics pose a serious threat to economies and livelihoods, it is imperative to understand how one prepares for something which may occur without sufficient warning. Infectious diseases and outbreaks need a resilient public health system, particularly a strong surveillance mechanism, adequate health personnel, sufficient medical supplies and equipment, and continuous training. A resilient health system has been defined as "the capacity of health actors, institutions, and populations to prepare for and effectively respond to crises; maintain core functions when a crisis hits; and, informed by lessons learnt during the crisis, reorganize if conditions require it" (Kruk et al. 2015). Pandemic prevention and management being a public good, it is the government which has to put in place a resilient system to manage outbreaks and epidemics.

Since the AIDS epidemic in the 1980s, the world has seen some major epidemics and pandemics: H1N1 or swine flu pandemic of 2009-2010, the West African Ebola epidemic in 2014-2016 and Zika virus which started in 2015 and is still around. India has also seen a series of outbreaks and epidemics, the recent ones being SARS, Avian influenza, Zika and Nipah virus, in addition to Chikungunya and dengue. Each time there were lessons to be learnt and models to be followed. The successful control of Nipah outbreak in Kerala was an important model for the rest of the country; Kerala's approach to its health system has been very different from that of most other states, enabling it to deal with outbreaks and epidemics much better (Sahay et al. 2020). Kerala's repsonse to COVID is also explained in detail in this volume (Jalan and Sen 2020). Suffice to say here that the effectiveness of Kerala's response is evidenced from the way it dealt with COVID-19: instead of waiting for the Centre's directions, Kerala moved swiftly to contain the pandemic by screening all arrivals, tracing contacts and adopting a robust testing strategy. It also shut down educational institutions and entertainment centres and banned large gatherings including religious ones (The Hindu 2020). The COVID-19 alert was issued as early as on January 18, 2020, much before the Central government had announced the lockdown, and by this time, many in Kerala had been put in isolation and quarantine and 30,000 healthcare workers had already been deployed (Tharoor 2020). The ICMR termed this the "Kerala model" for testing and containment strategies (Economic Times 2020a, b). Clearly, the state of preparedness in Kerala has been much superior compared to the rest of the country (Jalan and Sen 2020).

A number of studies exist that analyse pandemic preparedness in countries (Oshitani et al. 2008; Ortu et al. 2008; Hanvoravongchai et al. 2010). The WHO has initiated the Joint External Evaluation (JEE) as part of the International Health Regulations 2005 (IHR) process, to help countries to assess their ability to prevent, detect and respond to public health threats such as infectious disease outbreaks (WHO Joint External Evaluations 2005). The JEE is a voluntary exercise for countries to identify the most critical gaps within their health to better prepare for pandemics. 
The JEE mission reports are a good starting point to understand the gaps and priorities of various countries. Unfortunately, India's mission report is not available on the WHO website; it is possible that the exercise was not undertaken or completed by India. This, despite the fact that the ministerial meeting held in Delhi on Emergency Preparedness - named the Delhi Declaration of Emergency Preparedness-was adopted in September 2019 at the 72nd session of the WHO Regional Committee for South-East Asia (Ofrin et al. 2020) and presided over by the India's Health Minister, Dr Harsh Vardhan. India also pledged \$200,000 towards implementation of the preparedness stream (Press Information Bureau 2019).

It does seem, however, that India has been doing better at managing natural disasters than public health crises. Cyclone Fani, and more recently cyclone Amphan, are good examples of this. Early warning systems through surveillance and containment of outbreaks of epidemics in disaster zones have been very encouraging signals that India is now better able to manage natural disasters.

While a number of studies exist on the JEE and similar topics, a recent exercise to develop an Epidemic Preparedness Index (EPI) to assess national-level preparedness for pandemics for 188 countries was carried out (Oppenheim et al. 2019). The methodology included constructing five sub-indices for each country: public health infrastructure, physical infrastructure, institutional capacity, economic resources and public health communications. The results indicated that countries with low EPI scores are concentrated in West and Central Africa, Southwest Asia and areas within Southeast Asia. India gets a score of 3 in the EPI scores, with 1 denoting the category most prepared.

\subsection{Availability of hospital beds and out-patient care during COVID}

That India scores low on pandemic preparedness is hardly surprising: a look at some basic statistics on public health infrastructure (Table 3), including health personnel, shows how inadequate India's health system is-not only for pandemics and epidemics_-but in general for providing health care even during normal times.

The table presents three indicators of basic infrastructure and personnel for countries that have been impacted the most with COVID-19, and also reports government health spending out of GDP in the last column, which will be discussed subsequently.

India's physicians per 1000 and nurses per 1000 figures are lowest in this group. As for hospital beds per 1000 — a critical parameter at all times, but especially during the COVID crisis-India does extremely poorly. It is struggling to meet even the WHO norm of physicians which is 1 per 1000 population.

Some important indicators of low prioritisation of health can be directly seen from the status of health infrastructure and personnel in the country, obtained from the latest Rural Health Statistics. Figure 5 presents the shortfall in health personnel as a percentage of required manpower for doctors, various specialists, radiographers, health assistants, pharmacists and laboratory technicians for Primary Health Centres (PHC) and Community Health Centres (CHC) for rural and urban areas 
Table 3 Key health systems indicators for countries most impacted by COVID-19. Source: World Bank Data Bank

\begin{tabular}{lllll}
\hline Country & Physicians/1000 & $\begin{array}{l}\text { Nurses and mid- } \\
\text { wives/1000 }\end{array}$ & $\begin{array}{l}\text { Hospital } \\
\text { beds/1000 }\end{array}$ & $\begin{array}{l}\text { Govt health } \\
\text { spending as \% of } \\
\text { GDP }\end{array}$ \\
\hline China & 1.8 & 2.3 & 4.2 & 2.9 \\
Spain & 3.9 & 5.5 & 3.0 & 6.3 \\
Italy & 4.0 & 5.9 & 3.4 & 6.5 \\
France & 3.2 & 11.5 & 6.5 & 8.7 \\
Germany & 4.2 & 13.2 & 8.3 & 8.7 \\
UK & 2.8 & 8.3 & 2.8 & 7.7 \\
S. Korea & 2.4 & 7.0 & 11.5 & 4.4 \\
Turkey & 1.8 & 2.7 & 2.7 & 3.3 \\
Iran & 1.6 & 2.6 & 1.5 & 4.4 \\
India & 0.8 & 2.1 & 0.7 & 1.0 \\
\hline
\end{tabular}

The data pertains to the latest available estimates

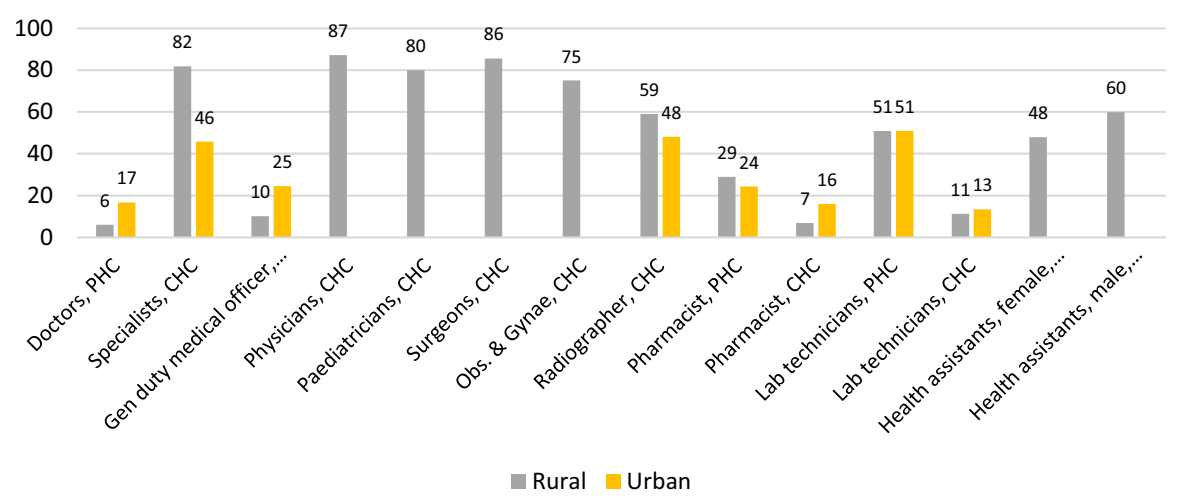

Fig. 5 Shortfall in health personnel (\%). Source: Rural Health Statistics 2018-19 (Govt. of India, Ministry of Health \& Family Welfare)

in 2019. For the urban areas, some of the comparable parameters are not availanble and, therefore, not shown in the chart.

The striking result is that there are significant shortfalls in personnel in both rural and urban areas, sometimes to the tune of $80-85 \%$ in some category of specialists.

There are significant shortfalls in infrastructure as well: for example, in rural areas, sub-centres (SC) and Health and Wellness Centres (HWC) are 23\% short, PHCs and HWC-PHC are $28 \%$ short and CHCs are $37 \%$ short respectively. In urban areas, there is a shortfall of $44 \%$ in PHCs. Many of the facilities are operating without the Indian Public Health Standard (IPHS) norms and are also deficient in amenities like regular water supply, electricity and all-weather motorable approach. 
Table 4 Treatment sought at type of facilities by ownership, NSS 75th round (\%)

\begin{tabular}{llll}
\hline Type of care & $\begin{array}{l}\text { Public facilities/consulta- } \\
\text { tions }\end{array}$ & $\begin{array}{l}\text { Private facilities/consulta- } \\
\text { tions }\end{array}$ & $\begin{array}{l}\text { Charitable/ } \\
\text { Trust/NGO }\end{array}$ \\
\hline Ailments, last 15 days & 30 & 66 & 4 \\
Hospitalisation & 42 & 55 & 3 \\
\hline
\end{tabular}

The state level picture varies a lot across these and other indicators like health workers, nursing staff and ASHA workers. While there are no discernible patterns, the data does show that for indicators like doctors and laboratory technicians at PHC, some of the hard hit states like Gujarat, Maharashtra and Tamil Nadu actually show a surplus. In fact, for a few types of health personnel in urban health facilities too, Delhi, TN, Gujarat and Maharashtra often show surpluses. On some other indicators, however, there continues to be deficits. Thus, a closer look at a wider array of parameters for states brings out the somewhat erratic and inconsistent variations, which probably explains why seemingly better-off states like Gujarat and Tamil Nadu ultimately do not fare that well in times of crisis.

With shortages of infrastructure and staff, it stands to reason that much of the demand will be met in the private sector. The elaborate public health infrastructure envisaged with population-based health infrastructure and personnel norms remained an unfulfilled promise of the Indian health care system, with concomitant rapid and unregulated expansion of the private sector to fill the void.

Table 4 corroborates this and indicates the huge dependence of the population on the private sector even for primary care.

Given this scenario, it was to be expected that COVID-care demand would have overwhelmed the government health care system. Based on the earlier discussion, it is clear that an equally important point is the impact COVID care would have on non-COVID care. Some straightforward calculations are helpful to elaborate on this point.

As per the National Health Profile 2019, there are about 26,000 hospitals and 7,20,000 beds in the government system (National Health Profile 2019); adding additional availability of hospital beds in railways and Employees' State Insurance Corporation or ESIC, there may be a total of 7,50,000 government beds. The NSS 75 th round data indicates a rate of hospitalization of $4.2 \%$ including child births in the sample. ${ }^{2}$

Table 5 gives the approximate estimates for annual demand for beds, with explanations given in the last column on how we arrive at the aggregates.

Based on various parameter values on beds in government hospitals, hospitalisation rate and duration of stay, there would have been an estimated $26 \%$ shortfall in available bed days in government hospitals, if patients only accessed public hospitals. The fact that only $42 \%$ of all patients actually go to public hospitals (Table 4),

\footnotetext{
${ }^{2}$ Since the beds include beds available at the primary care level, including child births in the rate of hospitalization is logical.
} 
Table 5 Estimates of annual demand for hospital beds and potential shortfall

\begin{tabular}{|c|c|c|}
\hline Parameters & Values & Comment and explanation \\
\hline Population...(1) & 1.38 billion & Projection for 2018 , census \\
\hline Beds in government hospitals...(2) & 750,000 & $\begin{array}{l}\text { Includes beds in ESIC, Railways } \\
\text { Source: National Health Profile }\end{array}$ \\
\hline $\begin{array}{l}\text { Beds days available in government hospitals in } \\
1 \text { year...(3) }\end{array}$ & 2.7 million & $(2) * 365$ \\
\hline $\begin{array}{l}\text { Rate of hospitalisation inclusive of child birth cases, } \\
\text { annual...(4) }\end{array}$ & $4.2 \%$ & Without childbirth, the rate is $2.9 \%$ \\
\hline Patients requiring hospitalisation in an year...(5) & 57 million & $(4) *(1)$ \\
\hline Duration of stay per hospitalisation...(6) & 6.4 days & NSS 75th round \\
\hline Bed days required...(7) & 0.371 billion & $(5) *(6)$ \\
\hline Shortfall in bed days...(8) & 98 million & (7) minus (3) \\
\hline Potential shortfall to total requirements...(9) & $26.4 \%$ & $(8) * 100 /(7)$ \\
\hline
\end{tabular}

indicate that the government system is not saturated and beds might remain vacant. There are clearly other reasons that make beds in government hospitals either inaccessible, potentially unavailable or simply unattractive for patients, many of who prefer to go to the private sector despite availability.

The relevance of these calculations is important in the context of COVID. Without the additional burden of COVID, there is already a shortage of beds in the government system, which is being met in private facilities with concomitant burden of treatment expenses on the patients. Even if we assume that there will be some overlap of the population that demands in-patient care with those in the additionaldemand-due to-COVID group, there will be a much larger total pool of hospitalseekers. With beds being now designated for COVID patients, it can only mean a squeezing out of in-patient care for non-COVID patients. Hospital stay for COVID19 patients can be for an average of 10-15 days, more than twice of the mean duration of stay during normal times, making turnover lower than usual.

It is possible that demand for non-COVID beds actually did not go up during the lockdown, which virtually cut off care-seeking behaviour with its concomitant effect on the most vulnerable, the elderly, but also on others. With the gradual removal of the lockdown and simultaneous increases in COVID case load, the pent up demand for care may lead to further squeezing out of care for non-COVID patients.

A recent study estimates the existing hospital capacity of India's public and private health sector in terms of number of hospital beds, Intensive Care Unit (ICU) beds, and ventilators, across States and Union Territories (Kapoor et al. 2020). The results indicate that distribution of beds and ventilators in India are uneven and mostly concentrated in seven States and also corroborate our findings that government facilities would not be sufficient to accommodate the influx of COVID-19 patients, and a rapid expansion of current capacity would be required.

The country has also witnessed the acute and distressing shortages of personal protective equipment (PPE) and other essential medical supplies, in addition to ventilators. Media has reported the increasing number of health workers getting infected 


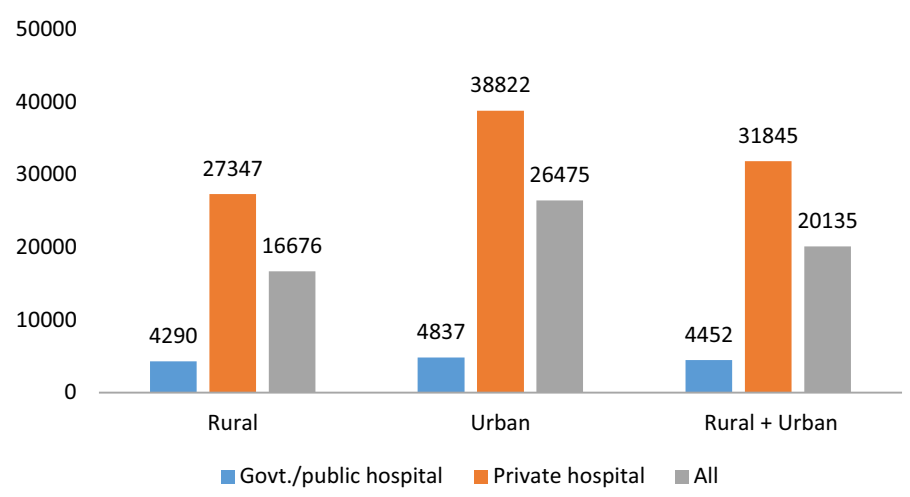

Fig. 6 Out-of-pocket medical expenditure per hospitalisation case by type of hospital (INR) NSS 75th round

due to lack of PPE in the early stages of the pandemic. When the pandemic started, India had almost zero capacity for producing PPE and very limited ventilators. During these 3-4 months, significant progress was made in procurement and augmentation of domestic manufacturing capacity in medical supplies (Times of India PTI 2020); (The Hindu Special Correspondent 2020).

The medical device industry depends on imports to the extent of almost $80 \%$ for its requirements (Department of Pharmaceuticals Annual Report 2019-2020) and there remains a paucity of Indian players in the manufacture of high-end medical devices, indicating a major constraint in meeting unanticipated demand. Now that there is evidence of domestic production being increased for some products, it is puzzling why this could not have been happened earlier by removing any technical or other barriers that may have impeded expansion of Indian production capabilities.

As for ambulatory care, a similar situation likely exists, though it is harder to pin down the exact ways in which this will work out. Anecdotally, many services are already not available (India Today 2020; The New Indian Express 2020) and services like dental surgeries have been impacted (Hindustan Times 2020a, b). Those who usually availed government OPD services - mostly those from the lower quintiles - may be forced to access private providers during COVID times or delay or postpone their visits with concomitant health consequences. While it is difficult to estimate the actual magnitude of the extra and displaced demand for COVID, the likely spill over to the private providers, with concomitant increase in out-of-pocket spending (OOPS), is going to impact most on the socioeconomically vulnerable classes. The differential between OOPS at public and private hospitals (Fig. 6) indicates that the difference was 6-8 times, with urban areas being worse off. It remains to be seen how this differential will be impacted post-COVID. 


\section{Health financing: a key control knob in health sector preparedness}

While there are many other indicators that can be discussed in the context of health sector preparedness, one key ingredient remains health financing. Even to strengthen other components like equipment and medical supplies, finance would remain a key control knob.

The neglect of the health sector is most evident in the low level of health financing over the years, indicating a serious lack of prioritisation. The last column of Table 3 presented earlier shows India's health expenditure of $1 \%$ of GDP compares poorly with other countries that are dealing with high COVID burden, like Germany, France and UK. While these countries may be some of the most developed, Table 6 shows India's health spending compares poorly even with the average of lower-middle income countries and with its neighbours in South and South-East Asia like Thailand and Sri Lanka. Middle income countries-a group to which India now belongs - spend on an average around 3\% of their GDP on health. India's value is similar to that of the least developed countries.

While the numbers are slightly different between the World Bank and domestic sources of data, Fig. 7-sourced directly from government documents-indicates

Table 6 Domestic general government health expenditure as a \% of GDP, 2017. Source: World Bank

\begin{tabular}{ll}
\hline World & 5.9 \\
Low income & 1.2 \\
Lower middle income & 1.3 \\
Middle income & 2.8 \\
Upper middle income & 3.3 \\
Thailand & 2.9 \\
Sri Lanka & 1.6 \\
Least developed countries & 1.0 \\
India & 1.0 \\
\hline
\end{tabular}

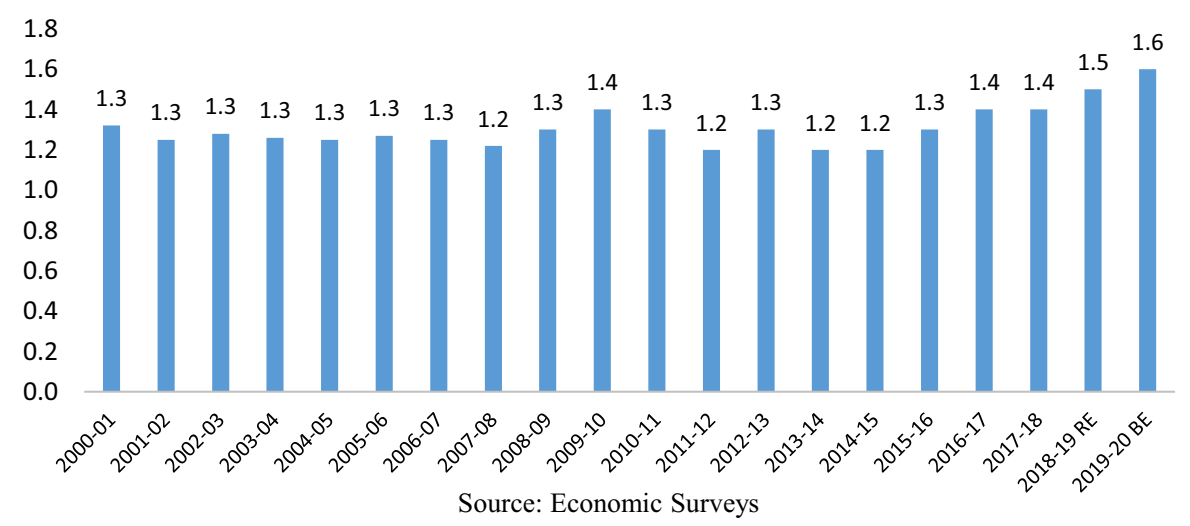

Fig. 7 Public health expenditure as a \% of GDP (Centre and States combined). Source: Economic Surveys (Govt. of India) 
Table 7 Government health expenditure, selected states (2017-2018 actuals). Source: RBI

\begin{tabular}{lcl}
\hline States & $\begin{array}{l}\text { Per capita public health } \\
\text { expenditure in rupees }\end{array}$ & $\begin{array}{l}\text { Health expendi- } \\
\text { ture as \% of } \\
\text { GSDP }\end{array}$ \\
\hline EAG & 927 & 1.2 \\
Non-EAG & 1292 & 0.7 \\
North eastern states & 3121 & 2.5 \\
Selected states & & \\
Bihar & 585 & 1.3 \\
Uttar Pradesh & 758 & 1.2 \\
Kerala & 1802 & 0.9 \\
Maharashtra & 996 & 0.5 \\
Gujarat & 1326 & 0.6 \\
Delhi & 2131 & 0.7 \\
Tamil Nadu & 1493 & 0.7 \\
\hline
\end{tabular}

that the level of spending out of GDP has not really changed over the years. The 2000-2001 and 2017-2018 actual were 1.3\% and 1.4\% of GDP respectively, indicating a static health sector investment.

The result of the continuous low level of investment in the health sector has resulted in India being dependent on OOPS as a major mode of health financing. As per the latest National Health Accounts, 63\% of current health expenditures are financed by household out-of-pocket payments in 2016-2017 (National Health Accounts 2019). Coupled with lack of health coverage for the majority of the population-also indicative of low public investment-India has landed itself in the unenviable group of countries that finances its health spending through private and not public funds.

An important point here is that the states bear the major brunt of health spending. According to the latest NHA, slightly less than $70 \%$ of total government health expenditure is incurred by state governments in 2016-2017. With about 1\% of GDP overall being spent on health between the centre and the states, the states could not be spending much on health either.

Table 7 presents government health expenditure in Gross State Domestic Product (GSDP) of Empowered Action Group (EAG), ${ }^{3}$ non-EAG and north-eastern states, and also a few selected states for 2015-2016. The non-EAG states are spending much less than $1 \%$ of their GSDP on health; this number is slightly better for EAG states at $1.2 \%$, though per capita expenditure is very low for this group. North-eastern states are doing much better, and spending almost $2.5 \%$ of their state incomes on health and spending substantially more per capita. If we look at the states hardest hit by COVID like Maharashtra, Delhi and Tamil Nadu—most of them are spending

\footnotetext{
3 Eight socioeconomically backward states, namely, Bihar, Chhattisgarh, Jharkhand, Madhya Pradesh, Orissa, Rajasthan, Uttaranchal and Uttar Pradesh, are referred to as the Empowered Action Group (EAG) states. These states account for about $46 \%$ of India's population and $61 \%$ of those living below the poverty line.
} 
less than $1 \%$ of their GSDP on the health sector. Kerala spends the most in this group, though still less than $1 \%$ of GSDP. Delhi's per capita expenditure is higher than that of other states, followed by Kerala.

Apart from the low level of prioritisation of health in states, this discussion also indicates that higher spending is necessary but may not be sufficient for better outcomes; Kerala managed to do well during COVID despite a modest level of health spending.

\section{Governance and health systems}

This brings us to a point that is often missed in discussions around spending: that of governance. Health systems, according to WHO, comprises six building blocks: health financing, human resources, medicines and technologies, health information, health service delivery and governance. Most discussions on health systems are around the first five blocks, with relatively much less said, written and analysed about governance of health systems. Partly this is because governance is difficult to define, quantify and measure, and there are quite a few alternative approaches to assess governance (Barbazza and Tello 2014). This is especially true of India, where published articles on governance are substantially fewer in number than those that discuss, for example, service delivery and health financing. Niti Aayog's Health Index Report estimates a composite rating based on 3 groups of indicators: health outcomes, governance and information, and key inputs/processes (Niti Ayog 2019). Unfortunately, due to paucity of data, the governance indicators are few and this group gets-relatively-a much lower weightage in the calculation of the health index. While overall, Kerala performs the best in terms of the composite index, it does not seem to be performing as well in the domain of governance. In the report, the overall performance of the states is not always consistent with the domain-specific performance.

However, a key feature of Kerala's overall governance has been a decentralised model, a variable that is notably not included in the Niti Ayog index under the domain of governance and information. The decentralised model started with the movement called People's Campaign for Decentralised Planning, and the subsequent Kerala Panchayat Act 1994 and Kerala Municipalities Act 1994 helped ensure that decentralised planning was there to stay in the state (Elamon et al. 2004). The participation of, and shouldering responsibility for various functions related to health, education, sanitation etc. at the local government level has been a key innovation in the governance space for Kerala. This has shaped the way health system in Kerala functions, and has enabled primary health care specifically, and public health generally to function in a more effective manner, compared to systems in other states (Chathukulam 2016).

In the case of the COVID response in India, whether this system of governance could have played a key role, is discussed elsewhere in this volume. It is not being contended here that decentralisation is the only parameter that determines superior governance, or that Kerala's is the only model of an effective health system. Tamil Nadu, which has been often hailed as the state with the best health system 


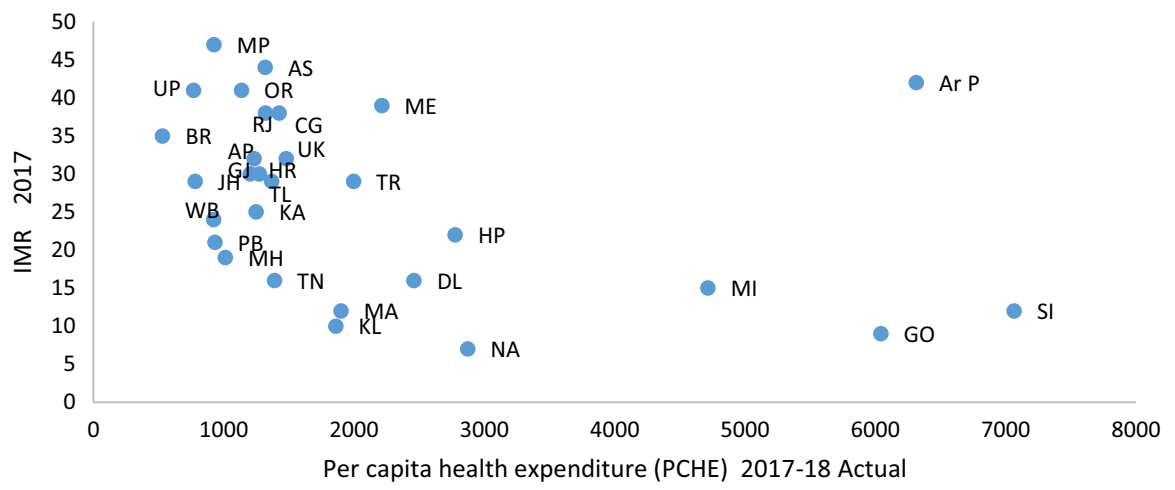

Fig. 8 Per capita health expenditure and IMR across states. Source: RBI \& National Health Profile (Govt. of India)

in the country - though its rank in the NITI Aayog health index has not been that high-has been struggling to deal effectively with one of the worst burdens of COVID in the country. One has been surprised at the vastly different ways the two states have responded to the COVID situation. TN's initial response has been termed tepid, with inadequate testing, and lacking in coordination between the state government and district administration, despite a good health system (Science, The Wire 2020). However, subsequently, the state has been able to improve testing significantly. Overall, Kerala showed superior management and maturity in its response, with results that are there for the world to see.

It stands to reason that there ought to be a strong correlation between the other building blocks and governance: better governed systems are likely to have better indicators on all the other building blocks generally. Better governed systems would achieve better health outcomes and a given level of health spending would bring in better outcomes in a better governed system, ceteris paribus. This can be gleaned to a certain extent by plotting an outcome like the Infant Mortality Rate (IMR) with per capita health expenditure (PCHE). Figure 8 does this for Indian states for the year 2017.

First of all, there is only a faint negative relationship between IMR and PCHE, indicating that merely raising health allocations is unlikely to bring in better health outcomes. There are two ways to read the figure. Kerala and Goa have similar PCHE but Kerala is able to achieve superior results in terms of IMR. Similarly, Meghalaya, Manipur, Tripura spend similar amounts per capita on health as Kerala, but Kerala manages to achieve the lowest IMR. Tamil Nadu and Delhi achieve similar IMR, but the former spends much less per capita to do so. The basic point is raising health spending is necessary but how the resources are spent is important; efficiency of resource use is a source of fiscal space for health resources as well (Tandon and Cashin 2010). This efficiency is likely to have a strong and positive relationship with governance, which admittedly, is difficult to measure. This is possibly an important explanation for Kerala's fairly successful response to COVID despite modest levels of health spending. 
A final point is about the status of India's fiscal federalism; recent debates and discussions have centred around the need for a new framework, the growing spatial inequalities in financial resources and the trust deficit between the Centre and the states (Chakraborty 2019; Bhanumurthy et al. 2019). The COVID crisis has brought to our attention another challenge: the extremely fragile relationship between the centre and the states, and the undeniable role that politics plays in challenging this fragile equation. The fiscal demands of responding to the crisis have overwhelmed the states, and of course, impacted on the centre's finances as well. This was the time for the centre to adopt a more empathetic approach to help states deal with the double impact of COVID: economic slowdown with resultant reduction in revenues, and increase expenditure to strengthen the health sector and initiate social welfare measures to ward off the serious losses to livelihoods caused by the lockdown and the halt to economic activities. The Centre has often unilaterally initiated a slew of measures that directly impact on the states' finances and ability to spend (Sen 2020; Ghosh 2020). States have been clamouring for more funds, including their share of GST, and some have outright questioned the adequacy of the fiscal and cash stimulus (The Telegraph India 2020). The role that the 15th Finance Commission (FFC) could have played during these times in fiscal empowerment of states has also been raised (Khan 2020). However, the FFC has recognized the vastly enhanced requirements of the health sector and a high level group of experts has been constituted to advise the FFC on the various aspects of the funding requirements (Press Information Bureau 2020).

In this altered scenario of stretched and reduced resources, it is not clear where the states are making adjustments and cuts in spending, and how they might be managing their health spending. The cuts in budgets of central ministries as also state departments would have impacted on all spending, including health. While the Centre had given some funds initially for health sector strengthening, these would have been grossly insufficient for the states that have been the most impacted, like Tamil Nadu, Maharashtra, Kerala and Delhi. With a more generous financial assistance, it is possible that the states would have responded more effectively. In fact, given that health is a state subject and that the pandemic is being played out differently in each state, the core of the response should have been an emphasis on decentralized planning and management of the pandemic, with centre lending its full support, financially as well as otherwise, with ideologies thrust aside. Instead, the states have been struggling to stay afloat in more ways than one, and only time will tell how each of them fared.

\section{Conclusions and looking forward}

The pandemic has hit India hard; while the health sector was discussed in detail here, one has to keep in mind the severe shock imparted to the economy and livelihoods because of COVID that has shaken up the very foundations on which the Indian economy and society stood. The end is not yet in sight and it is still hard to predict when the peak will come. While continued lockdown is not feasible any more from an economic perspective, to put the pieces back for millions of workers 
and others would take a long time, and the aftermath of the pandemic will be felt for many months to come.

Finances would remain a major issue - for the health sector and for all other sectors - whether directly impacted or not. In the midst of all this, it is hard to visualize any amendment to our current health policy and to even move towards the promised jump to $2.5 \%$ of GDP in government health financing envisaged by 2025 or increase in state sector health spending to more than $8 \%$ of their budgets by 2020 (MOHFW 2017). In fact, $2.5 \%$ of GDP by 2025 is going to be quite inadequate: India will need to revise this number and think of at least $4-5 \%$ of GDP allocated to health if the health system has to be strengthened to bear the brunt of future pandemics and epidemics.

It is just not financing; years' of neglect of the public health infrastructure and services has been causing irreparable damage by denying people of quality and accessible health care. The rapid increase in the private sector to fill the void left by the public sector has happened in an unregulated environment, and less than half the states/UTs have actually adopted and implemented the only piece of regulation that governs health facilities - the Clinical Establishment Act. The major brunt has been borne by the less privileged who have been forced to go to a variety of private providers of uneven quality and incur expenditures they can ill afford. Many have possibly not sought care at all due to access and cost concerns.

A country cannot deal effectively with a pandemic by trying to fix its health systems in real time. Each life is precious, and to lose lives because of poor and unavailable products and services is unpardonable. The fixing had to be done much ahead of time. In addition to finances, the overhaul of the health system in the country require reforms that are fundamental in a number of areas: medical education, primary health care, the referral system, infrastructure and personnel, public health cadre, administration of health services - the list is long. Instead of undertaking a series of incremental reforms in each of these areas, the country has been initiating schemes and programmes, with newer schemes thrust on the population without changing the underlying flawed fundamentals. In any case, finances have not been forthcoming to match these various new schemes, even in the latest budget. With ambitious programmes like the Health and Wellness Centre (HWC) and Prime Minister's Jan Arogya Yojana (PM-JAY) under Ayushman Bharat, financially sustainability would remain a key concern (Gupta et al. 2019).

In fact, post-COVID, it is not clear how these schemes will continue in a muchreduced resource envelope, without cutting down on other essential health investments. But more than that, the effectiveness of such initiatives can be much enhanced if implemented in a reformed health system. While Universal Health Coverage (UHC) has been a much discussed concept and schemes like PMJAY have been positioned as a step towards it, India is still a long way off from achieving UHC, precisely because the reforms have not taken place. Countries like Thailand (Tangcharoensathien et al. 2019) have shown how incremental reforms that often went against entrenched political interests do work if government seriously wants to implement UHC. Movement towards UHC is a continuous long term one fraught with political economy challenges (Reich et al. 2016). That could be a reason why 
health initiatives have been more scheme or programme-based in India, instead of reforms that attempt fundamental changes in the way the health sector operates.

India does not need another pandemic to wake up to the urgent need for health sector reforms and health systems strengthening. Nor does it need a reminder that its health allocations are pitiful, requiring not a marginal-but a substantial jump-in the level of government spending on health. While both the centre and the states need to work on these reforms, the role of decentralized policymaking-where states can take decisions that are in their best interests-need to take centre stage, especially since health is a state subject. The union government requires to provide the overall financial and regulatory framework, allowing the states to take charge of their own health sectors. The pandemic has repeatedly thrown up examples of conflict and confusion in decision-making that need not have taken place if the two levels of governments could have worked in a cooperative-rather than adversarialmode. It can only be hoped that in the coming months, some hard decisions would be taken up by the government, with cooperative federalism as the guiding principle, to fundamentally alter the way the health sector is governed and prioritised.

Acknowledgements The author is grateful to J. V. Meenakshi for her insightful and constructive comments on an earlier draft of the paper. Research help extended by Devmani Upadhyay, Avantika Ranjan and Arjun Roy is acknowledged with thanks.

\section{References}

Barbazza, E., \& Tello, J. E. (2014). A review of health governance: Definitions, dimensions and tools to govern. Health Policy, 116, 1-11.

Bhanumurthy, N. R., Reddy, Y. V., \& Reddy, G. R. (2019). Indian fiscal federalism. Indian Economic Review, 54, 193-195.

Burn-Murdoch, R. \& Giles, C. (2020). UK suffers second-highest death rate from coronavirus. Financial Times. May. https://www.ft.com/content/6b4c784e-c259-4ca4-9a82-648ffde71bf0.

Centers for Disease Control and Prevention. (2020). Provisional COVID-19 death counts by sex, age, and state.

Chakraborty, L. (2019). Indian fiscal federalism at the crossroads: Some reflections. New Delhi: National Institute of Public Finance and Policy. Working Paper No. 260.

Chathukulam, J. (2016). Reflections on decentralised health delivery system in Kerala (vol. LIV, No. 6). New Delhi: Mainstream.

Chudasama, Y. V., Gillies, C. L., Zaccardi, F., Coles, B., Davies, M. J., Seidu, S., et al. (2020). Impact of COVID-19 on routine care for chronic diseases: A global survey of views from healthcare professionals. Diabetes \& Metabolic Syndrome, 14(5), 965-967.

Dandona, L., Dandona, R., Kumar, G. A., Shukla, D. K., Paul, V. K., \& Balakrishnan, K. (2017). Nations within a nation: Variations in epidemiological transition across the states of India, 1990-2016 in the Global Burden of Disease Study. The Lancet, 390(10111), 2437-2460.

Department of Pharmaceuticals Annual Report. (2019-2020). Ministry of Chemicals and Fertilizers. (2019-2020)

Devi, D., \& Milevska-Kostova, N. (2020). Cancer medicine: A missed opportunity. The Lancet, 395, 1257-1258. https://doi.org/10.1016/S0140-6736(20)30175-6.

Economic Times. (2020). ICMR lauds Kerala's containment strategy for COVID-19. May 02.

Elamon, J., Franke, R. W., \& Ekbal, B. (2004). Decentralization of health services: The Kerala People's Campaign. International Journal of Health Services, 34(4), 681-708. https://doi. org/10.2190/4L9M-8K7N-G6AC-WEHN.

Ghosh, K. S. (2020). Erosion of fiscal federalism in the times of Covid-19. The Hindu Business Line. https://www.thehindubusinessline.com/opinion/erosion-of-fiscal-federalism-in-the-times-of-covid -19/article31670568.ece\#. Accessed 1 June 2020. 
Gupta, I. (2020). Relying on serendipity is not enough: Fixing the health system in India for future pandemics. IEG Insights, 29-37. Retrieved from https://iegindia.org/upload/uploadfiles/insight_covid _2.pdf. Accessed 20 July 2020.

Gupta, I., Chowdhury, S., Ramandeep, A. R. (2019). Ayushman Bharat Costs and Finances of the Prime Minister's Jan Arogya Yojana (PMJAY). Report submitted to Fifteenth Finance Commission. (2020). Retrieved from https://fincomindia.nic.in/ShowContentOne.aspx?id=27\&Section=1.

Hanvoravongchai, P., Adisasmito, W., Chau, P. N., Conseil, A., de Sa, J., Krumkamp, R., Mounier-Jack, S., Phommasack, B., Putthasri, W., Shih, C. S., Touch, S., Coker, R., \& AsiaFluCap Project. (2010). Pandemic influenza preparedness and health systems challenges in Asia: Results from rapid analyses in 6 Asian countries. BMC Public Health, 10, 322.

Harky, A., Chiu, C. M., Yau, T. H. L., \& Lai, S. H. D. (2020). Cancer patient care during COVID-19. Cancer Cell, 37, 749.

Hindustan Times. (2020). Covid-19 impacts dental surgeries, patients forced to suffer in pain. https:// www.hindustantimes.com/india-news/covid-19-impacts-dental-surgeries-patients-forced-to-suffe r-in-pain/story-O7C5iMFVYNG9SOITJ04teK.html. Accessed 15 May 2020.

India Today. (2020). Agonising wait for non-Covid patients in Delhi. https://www.indiatoday.in/mailtoday/story/agonising-wait-for-non-covid-patients-in-delhi-1668256-2020-04-18. Accessed 15 May 2020.

Indian Council of Medical Research (ICMR). (2020). Laboratory Details. List of Covid-19 Testing Govt. and Pvt. Labs. https://www.icmr.gov.in/pdf/covid/labs/COVID_Testing_Labs_30062020_1.pdf. Accessed 30 June 2020.

Institute for Health Metrics and Evaluation (IHME). (2018). India. Seattle, WA: IHME, University of Washington, 2018. Retrieved from July 07, 2020. https://www.healthdata.org.

Jalan, J., \& Sen, A. (2020). Containing a pandemic with public actions and public trust: the Kerala story. Indian Economic Review. https://doi.org/10.1007/s41775-020-00087-1.

Kapoor, G., Hauck, S., Sriram, A., Joshi, J., Schueller, E., Frost, I., Balasubramanian, R., Laxminarayan, R., Nandi, A. (2020). State-wise estimates of current hospital beds, intensive care unit (ICU) beds and ventilators in India: Are we prepared for a surge in COVID-19 hospitalizations? Centre for Disease Dynamics Economics and Policy (CDDEP). April 20. https://cddep.org/wpcontent/uploa ds/2020/04/State-wise-estimates-of-current-beds-and-ventilators_20Apr2020.pdf.

Khan, J. A. (2020). Missing Spirit of Cooperative Fiscal Federalism to Fight COVID-19. Centre for Budget and Governance Accountability (CBGA) Opinions. https://www.cbgaindia.org/blog/missi ng-spirit-cooperative-fiscal-federalism-fight-covid-19/. Accessed 15 June 2020.

Kruk, M. E., Michael, M., Varpilah, S. T., \& Dahn, B. T. (2015). What is a resilient health system? Lessons from Ebola. The Lancet, 385(9980), 1910-1912.

Ministry of Health and Family Welfare. (2017). National Health Policy 2017. https://main.mohfw.gov.in/ sites/default/files/9147562941489753121.pdf.

Ministry of Health and Family Welfare, Central Bureau of Health Intelligence, National Health Profile. (2019). Directorate General of Health Services.

NDTV. (2020). Amit Shah says no COVID-19 community transmission in Delhi. https://www.ndtv.com/ india-news/manish-sisodia-said-delhi-will-have-5-5-lakh-covid-19-cases-by-july-31-this-createdfear-among-public-amit-shah-to-ani-2253518. Accessed 29 June 2020.

Niti Ayog. (2019). Healthy States Progressive India. Report on the ranks of States and Union Territories.

Ofrin, R. H., Bhola, A. K., \& Buddha, N. (2020). Turning commitments into actions: Perspectives on emergency preparedness in South-East Asia. WHO South-East Asia Journal of Public Health, 9(1), 5-14.

Oppenheim, B., Gallivan, M., Madhav, N. K., Brown, N., Serhiyenko, V., Wolfe, N. D., et al. (2019). Assessing global preparedness for the next pandemic: Development and application of an Epidemic Preparedness Index. BMJ Global Health, 4(1), e001157.

Ortu, G., Mounier-Jack, S., \& Coker, R. (2008). Pandemic influenza preparedness in Africa is a profound challenge for an already distressed region: Analysis of national preparedness plans. Health Policy Plan, 23(3), 161-169.

Oshitani, H., Kamigaki, T., \& Suzuki, A. (2008). Major issues and challenges of influenza pandemic preparedness in developing countries. Emerging Infectious Diseases, 14(6), 875-880.

Press Information Bureau. Ministry of Health \& Family Welfare. (2019). Dr. Harsh Vardhan presides over Ministerial Roundtable on "Emergency Preparedness" at 72nd Session of WHO Regional Committee for South-East Asia. 3 September. https://pib.gov.in/PressReleasePage.aspx?PRID=1583972. 
Press Information Bureau. Ministry of Health and Family Welfare. (2020). Meeting of the Fifteenth Finance Commission with its High Level Group on Health Sector. 20 May. https://pib.gov.in/Press ReleaseIframePage.aspx?PRID=1625371.

Reich, M. R., Harris, J., Ikegami, N., Maeda, A., Cashin, C., Araujo, E. C., et al. (2016). Moving towards universal health coverage: Lessons from 11 country studies. The Lancet, 387, 811-816.

Sahay, R., Yadav, P., Gupta, N., Shete, A., Radhakrishnan, C., Mohan, G., et al. (2020). Experiential learnings from the Nipah virus outbreaks in Kerala towards containment of infectious public health emergencies in India. Epidemiology and Infection, 148, E90.

Sen, P. (2020). Covid-19: Consequences for state finances. Ideas for India. https://www.ideasforindia.in/ topics/governance/consequences-of-covid-19-on-state-finances.html. Accessed 15 June 2020.

Singh, A. K., Gupta, R., \& Misra, A. (2020). Comorbidities in COVID-19: Outcomes in hypertensive cohort and controversies with renin angiotensin system blockers. Diabetes \& Metabolic Syndrome: Clinical Research \& Reviews., 14(4), 283-287.

Tandon, A., Cashin, C. (2010). Assessing public expenditure on health from a fiscal space perspective. Health, Nutrition and Population (HNP) discussion paper. Washington, D.C.: World Bank Group. https://documents.worldbank.org/curated/en/333671468330890417/Assessing-public-expen diture-on-health-from-a-fiscal-space-perspective. Accessed 29 May 2020.

Tangcharoensathien, V., Patcharanarumol, W., Kulthanmanusorn, A., Saengruang, N., \& Kosiyaporn, H. (2019). The political economy of UHC reform in Thailand: Lessons for low- and middle-income countries. Health Systems \& Reform, 5(3), 195-208. https://doi.org/10.1080/23288604.2019.1630595.

Tharoor, S. (2020). Project Syndicate. https://www.project-syndicate.org/commentary/kerala-model-forbeating-covid-19-by-shashi-tharoor-2020-05?barrier=accesspaylog.

The Hindu Special Correspondent. (2020). https://www.thehindu.com/news/national/covid-19-bel-tomake-30000-ventilators-within-two-months-defence-ministry/article31377555.ece.

The Hindu. (2020). The mark of zero: On containment of COVID-19 cases in Kerala. May 06. https:// www.thehindu.com/opinion/editorial/the-mark-of-zero-on-containment-of-covid-19-cases-inkerala/ article31512638.ece.

The New Indian Express. (2020). OPDs open in Delhi, visit at your own risk. https://www.newindiane xpress.com/cities/delhi/2020/may/25/opds-open-in-delhi-visit-at-your-own-risk-2147656.html.

The Telegraph India. (2020). Bengal ahead of rest: Amit Mitra. https://www.telegraphindia.com/busin ess/bengal-ahead-of-rest-during-coronavirus-lockdown-amit-mitra/cid/1781456.

The Wire. Science. (2020). COVID-19: Tamil Nadu Fumbles as Cases Surge, in Chennai and Elsewhere. Retrieved from https://science.thewire.in/health/covid-19-cases-spike-tamil-nadu-government -mismanagement-chennai-lockdown/. Accessed 1 June 2020.

Times of India. (2020). Community transmission of Covid-19 on in many parts of India. June 13. https:// timesofindia.indiatimes.com/india/community-transmission-of-covid-19-on-in-many-parts-of-india icmr-survey-not-reflective-of-current-realityexperts/articleshow/76355865.cms\#: :text=The\%20ass ertion $\% 20$ by $\% 20$ experts $\% 20$ from, while $\% 20$ releasing $\% 20$ the $\% 20$ findings $\% 20$ of.

Times of India PTI. (2020). Covid-19: Govt orders 60,884 ventilators, of which 59,884 to be made by domestic firms. https://timesofindia.indiatimes.com/articleshow/75494999.cms?utm_source=conte ntofinterest\&utm_medium=text\&utm_campaign=cppst.

Wang, B., Li, R., Lu, Z., \& Huang, Y. (2020). Does comorbidity increase the risk of patients with COVID-19: Evidence from meta-analysis. Aging, 12(7), 6049-6057.

World Health Organization (WHO) Diseases. (2020). Emergencies preparedness, response. https://www. who.int/csr/disease/swineflu/frequently_asked_questions/pandemic/en/

World Health Organization (WHO) Humanitarian Health Action. (2020). Definitions: emergencies. Retrieved from https://www.who.int/hac/about/definitions/en/. Accessed 15 June 2020.

World Health Organization (WHO) Joint External Evaluations. (2005). Strengthening health security by implementing the International Health Regulations.

World Health Organization (WHO) Newsroom Commentaries Detail. (2020). Multisystem inflammatory syndrome in children and adolescents with Covid-19.

Zhao, Q., Meng, M., Kumar, R., Wu, Y., Huang, J., Lian, N., et al. (2020). The impact of COPD and smoking history on the severity of COVID-19: A systemic review and meta-analysis. Journal of Medical Virology. https://doi.org/10.1002/jmv.25889.

Publisher's Note Springer Nature remains neutral with regard to jurisdictional claims in published maps and institutional affiliations. 